\title{
Dilemas atuais da sociedade brasileira sob as lentes da antropologia: relato de experiência de uma disciplina do curso de graduação em saúde coletiva da UFRJ
}

\section{Current dilemmas of Brazilian society through the lenses of anthropology: an experience report in a discipline from the UFRJ Collective Health Graduation Course}

\author{
Jaqueline Ferreira ${ }^{a}$ \\ (D) https://orcid.org/0000-0002-7662-1773 \\ E-mail: jaquetfळgmail.com \\ Lucas Tramontano ${ }^{a}$ \\ (iD) https://orcid.org/0000-0002-8141-0401 \\ E-mail: lucas.tramontanoळgmail.com

\section{Ana Paula Klein ${ }^{\mathrm{a}}$} \\ (D) https://orcid.org/0000-0002-6990-7765 \\ E-mail: anakleinळiesc.ufrj.br \\ aniversidade Federal do Rio de Janeiro. Instituto de Estudos em \\ Saúde Coletiva. Rio de Janeiro, RJ, Brasil.
}

\section{Correspondência}

Jaqueline Ferreira

Avenida Horácio Macedo, S/N, Ilha do Fundão - Cidade Universitária. Rio de Janeiro, RJ, Brasil. CEP 21941-598

\section{Resumo}

A antropologia brasileira tem se debruçado sobre o multiculturalismo, a diversidade social e a desigualdade econômica no país. Os estudos antropológicos sobre essas questões muito contribuíram para inseri-las nos debates mais amplos sobre os problemas sociais brasileiros. Este artigo trata de um relato de experiência de ensino em duas ofertas da disciplina Atividades Integradas em Saúde Coletiva (Aisc) II para bacharelandos do segundo período do curso de graduação em saúde coletiva da Universidade Federal do Rio de Janeiro. A disciplina busca trazer à discussão problemas sociais emergentes da sociedade brasileira, como racismo, intolerância religiosa, saúde da população transexual e violência doméstica. Por meio de rodas de conversa com ativistas e visitas a locais de militância, os alunos realizam observação participante e conhecem suas lutas e reivindicações. Introduzindo conceitos caros à antropologia, como etnocentrismo, relativismo e movimentos sociais, pretende-se estimular nos estudantes uma reflexão crítica sobre dilemas sociais contemporâneos. Os debates, os relatos e as trocas de experiências advindos no decorrer da disciplina mostram que a antropologia tem muito a contribuir para uma formação e atuação mais dialógica desses futuros sanitaristas com as populações às quais prestarão cuidado, além de favorecer uma compreensão mais aplicada do 
impacto das desigualdades sociais no processo saúde-doença.

Palavras-chave: Ensino; Antropologia; Saúde Coletiva; Ativismo Político; Problemas Sociais.

\section{Abstract}

The Brazilian anthropology has focused on multiculturalism, social diversity and economic inequality in the country. Anthropological studies on these issues have greatly contributed to inserting it into broader debates about Brazilian social problems. This article deals with a report taken from two semesters teaching experience of the Integrated Activities of Collective Health II discipline for second period bachelor's degree students of the graduate course in collective health of Universidade Federal do Rio de Janeiro. The discipline aims at discussing emerging social problems in Brazilian society such as racism, religious intolerance, health of the transsexual population and domestic violence. Through conversations with activists and meetings in militance sites, students engage in participant observation and know their struggles and demands. Introducing important concepts to anthropology, such as ethnocentrism, relativism and social movements, it is intended to stimulate a critical reflection on contemporary social dilemmas in the students. The debates, reports and experiences exchanges emerged during the discipline course reveal that anthropology has a lot to contribute to a more dialogical formation and action of these future public health workers among the population of whom they will take care, besides favoring a more applied understanding on the impact of the social inequalities on the health-disease process. Keywords: Teaching; Anthropology; Collective Health; Political Activism; Social Problems.
Esse artigo trata de um relato de experiência de ensino em duas ofertas da disciplina Atividades Integradas em Saúde Coletiva II (Aisc II) para bacharelandos do segundo período do curso de graduação em saúde coletiva da Universidade Federal do Rio de Janeiro (UFRJ). O objetivo aqui é refletir sobre o potencial da antropologia para a formação dialógica desses futuros sanitaristas com as populações às quais prestarão cuidado, além de favorecer uma compreensão mais aplicada do impacto das desigualdades sociais no processo saúde-doença. 0 estudo se baseia na experiência docente de vários anos nessa disciplina e na reflexão sobre a literatura especializada.

Essa experiência suscita questões sobre a relevância do ensino das ciências sociais e humanas, particularmente a antropologia, nas graduações das ciências da saúde. Assim, qual é a pertinência da cisão entre teoria e prática no ensino em saúde, cisão essa muito prevalente nas visões dos profissionais de saúde (e, por que não dizer, na de muitos docentes e pesquisadores)? Antes de entrar no debate propriamente dito, gostaríamos de descrever brevemente a introdução e as características da disciplina Aisc para bacharelandos do segundo período da graduação em saúde coletiva da UFRJ. Os nomes de alunos citados são fictícios.

\section{A graduação em saúde coletiva na UFRJ e as disciplinas de Ações Integradas em Saúde Coletiva}

O curso de graduação em saúde coletiva na UFRJ iniciou em 2009, após amplo debate de profissionais, que reconheciam a necessidade da criação de uma formação que incorporasse saberes e práticas sanitaristas desde a graduação, e não somente na pós-graduação (Lorena et al., 2016). Ele visa formar profissionais com habilidades e conhecimentos diversificados, capacitando-os a atuar no planejamento, na gestão e na execução de ações em saúde coletiva. De acordo com o projeto político-pedagógico (PPP) do curso,

Sua formação deverá lhe proporcionar uma visão integrada das relações entre os elementos dos 
meios ecológico, sociocultural, econômico e político sabendo utilizar os conhecimentos adequados no trato das questões de saúde da coletividade, das necessidades da sociedade, respeitando sua diversidade cultural, de forma a facilitar o diálogo entre os diferentes interesses e setores. (UFRJ, 2010, p. 17)

Com uma grade curricular ampla, pautada no tripé formado por (1) epidemiologia, (2) planejamento, políticas públicas e gestão e (3) ciências humanas e sociais em saúde, o curso conta com uma disciplina voltada a atividades práticas que percorre os oito períodos da graduação intitulada Aisc. Essa disciplina tem como objetivo aproximar os alunos dos campos de prática da saúde. Seu objetivo é a mediação entre realidade e conhecimento empírico para a compreensão da complexidade das realidades de saúde da população. Nesse contexto, é importante o aprendizado da complexidade social, o reconhecimento do contexto sociocultural e as especificidades das ações de intervenção em saúde neste.

De acordo com o PPP, as Aisc atendem os pressupostos de Morin (2006), que defende como a educação do futuro necessita de uma adequação mais ampla, profunda e intensa dos saberes divididos e compartimentados e das realidades ou problemas, cada vez mais multidisciplinares, transversais, multidimensionais, transacionais e globais. Em se tratando de saúde coletiva, é preciso uma compreensão que incorpore a perspectiva social na formação e nas atividades dos sanitaristas; essa compreensão deve transcender a formação biomédica tradicional e atender aos diversos desafios e perspectivas da saúde pública do país. Ainda segundo o PPP,

A produção, identidade, compromisso e compreensão da origem e evolução dos problemas que a saúde das populações enfrenta, assim como a complexidade dos processos de negociação, fragmentação e descontinuidade que se produzem no processosaúde doença são as prioridades deste curso. (UFRJ, 2010, p. 18)
Dessa forma, o planejamento e a organização das Aisc foram realizados da seguinte forma até o presente momento: no primeiro período da graduação, os alunos fazem visitas técnicas a Unidades Básicas de Saúde (UBS), hospitais e maternidades, Centros de Atenção Psicossocial e ambulatórios. No segundo período, eles fazem visitas a organizações da sociedade civil, militâncias e projetos sociais, e realizam debates de temas sociais emergentes. No terceiro período, os alunos visitam e participam da rotina da Estratégia Saúde da Família. No quarto, eles realizam um mapeamento da rede de serviços de atenção à saúde e constroem o itinerário terapêutico de um usuário do Sistema Único de Saúde (SUS). No quinto e sexto período, se debruçam na vigilância sanitária - e, no sétimo e oitavo, escolhem um campo de interesse para realizar estágio ao longo do ano.

Este artigo debruça-se sobre o relato de experiência na disciplina de Aisc ofertada no segundo semestre do curso (Aisc II). ${ }^{1} \mathrm{O}$ interesse aqui é apresentar aos alunos problemas sociais emergentes com o intuito de proporcionar uma reflexão crítica sobre a realidade e transmitir a eles as relações complexas da saúde com esses temas e como elas são inscritas em uma dimensão social e política. Para isso, a disciplina foi estruturada com visitas a instituições e debates com lideranças de movimentos e lutas, algo que iremos detalhar mais adiante. A presença de atores e visitas aos espaços dos referidos movimentos buscam conhecer suas demandas específicas e proporcionar a reflexão dos alunos sobre temáticas prementes do Brasil contemporâneo e sua relação com a saúde coletiva.

Dessa forma, a disciplina objetiva apresentar, discutir e refletir sobre aspectos conceituais e históricos dos movimentos sociais e das organizações da sociedade civil no que se refere à construção das políticas de saúde, bem como tópicos relativos a lutas, engajamentos, mobilizações e conflitos na esfera pública. Objetiva também apresentar outros campos de atuação da saúde coletiva além dos órgãos estatais e do SUS. Pensar esses temas e questões pelo ângulo da antropologia supõe perceber como

\footnotetext{
1 Um relato de experiência da disciplina Atividades Integradas em Saúde Coletiva IV (Aisc IV) pode ser encontrado em Kurokawa Silva, Ventura e Ferreira (2013).
} 
noções, conceitos e a perspectiva de minorias e suas lutas são parte de construções sociais dentro de processos históricos. Solicitamos igualmente aos alunos que apresentem um relatório de cada visita ou roda de conversa com algum convidado. Esse relatório é orientado de acordo com algumas noções de observação participante que oferecemos no início do curso. Estimulamos, assim, os alunos a descrever o espaço, as interações e suas próprias percepções e sentimentos em relação ao contexto, servindo-se de um diário de campo.

Segundo Durkheim (1994), na medida em que as pessoas pertencem a grupos sociais e culturas determinadas, suas ações tendem a ser representativas daquele grupo, colocando em questão a espontaneidade das ações sociais. No que concerne à antropologia, o pensamento relacional permitiu colocar em xeque certos determinismos, como o biológico, que é o que nos diz respeito em relação ao ensino na formação de profissionais de saúde. Essas premissas básicas são igualmente importantes para o desvelamento de fenômenos relativos às desigualdades sociais como se fossem naturais, atribuindo as diferenças de oportunidades ao acaso do destino. Esse é o principal desafio da antropologia para essa disciplina.

Antes de iniciarmos o relato da disciplina propriamente dita, cabem aqui algumas reflexões que surgiram ao longo dos anos de experiência docente nessa matéria. A primeira delas diz respeito ao caráter teórico e prático do ensino das ciências sociais em saúde.

\section{As ciências sociais no ensino em saúde: o lugar da teoria e da prática}

De acordo com Barros (2008, p. 1054) os modelos de ensino das ciências sociais e da saúde são insuficientes para as necessidades da área da saúde, pois ora privilegiam o polo reflexivo, ora o prático, e nossa prática exige "métodos prático-reflexivos em diferentes cenários formativos".

A introdução das ciências sociais em geral no ensino da saúde ocorreu pela importância e legitimidade que elas vêm adquirindo com o tempo e pela necessidade de compreensão dos eventos de saúde de forma mais ampliada em relação aos focos exclusivamente biológicos. Essa relação ficou mais evidente no campo da educação em saúde, no qual foi necessário o ensino de propostas de ações com capacidade de atingir populações com características sociais e culturais distintas dos profissionais atuantes em saúde (Nunes et al., 2003). Da mesma forma, o impacto dos determinantes sociais na saúde valorizou os conhecimentos dessa área para o ensino na saúde.

No entanto, há ainda discrepâncias nos temas e na forma como os conteúdos devem ser abordados. Um dos pontos principais desse debate são, como lembra Barros (2008), os diferentes entendimentos e valorações que profissionais de saúde e cientistas sociais atribuem ao teórico e ao prático. 0 autor chama atenção para o fato de que a razão dessa discrepância se situa na base lógica intervencionista e prescritiva das ciências da saúde, mesmo sob o discurso da prevenção e promoção da saúde, em contraponto ao discurso reflexivo das ciências sociais. Ele defende que o conhecimento deve abranger os dois polos, uma vez que, para identificar os problemas sociais que influem no biológico, é necessário historicizá-los e compreendê-los em sua dimensão tanto simbólica quanto material.

Para Minayo et al. (2003), essa cisão é consequência da polaridade entre natureza e cultura que está na base da ciência moderna. Segundo as autoras, essa é a razão do conhecimento das ciências sociais não ter o mesmo prestígio que o conhecimento epidemiológico.

Barros (2008) ainda chama atenção para o modo como os alunos das ciências da saúde (sobretudo da medicina) avaliam como conflituosa a abordagem reflexiva das ciências sociais em relação aos protocolos técnicos das ciências da saúde. Dessa maneira, há mais de um século, Virchow e Canguilhem defendiam a profissão da saúde como ciência social. No entanto, há dificuldade em incorporar essa perspectiva, tendo em vista a cisão entre o social e o biológico, com supremacia deste em nossa cultura científica moderna. Defendemos aqui não uma inversão dessa supremacia, com preponderância das ciências sociais sobre as da saúde, mas a complementariedade entre as duas, de forma a garantir um conhecimento mais abrangente, com perspectivas de práxis mais reflexivas e humanizadas. 
Cabe aqui resgatar também que a própria questão do conhecimento teórico é parte da cultura, como bem refere Nunes (2014) ao resgatar a tradição da Grécia Antiga. Da mesma forma, a própria produção de fatos científicos é influenciada fortemente pela cultura, como já mostraram Latour e Woolgar (1988) na obra A vida de laboratório: a produção dos fatos científicos.

Desenvolver esses conteúdos não é fácil, uma vez que os entraves são reproduzidos no próprio currículo e nas prerrogativas das coordenações dos cursos das ciências da saúde. No que se refere especificamente à disciplina de Aisc II, para vencer essas barreiras, é necessário ampliar os conteúdos do campo da saúde, incorporando temáticas sociais relevantes e conhecimentos advindos de outros atores sociais, como os usuários dos serviços de saúde e ativistas dos movimentos sociais, além dos próprios pesquisadores e profissionais de saúde.

\section{o foco em desigualdades sociais, movimentos sociais e participação popular}

Pensar a educação em saúde sob o ponto de vista dos movimentos sociais, proposta da Aisc II, decorre da percepção da relação estreita entre a participação popular na saúde e a noção de desigualdades sociais em saúde. Conforme destacado por Costa e Vieira (2013), a saúde é objeto histórico de ação e demanda dos movimentos sociais. Contudo, para que compreendamos essa relação atualmente, é útil refletirmos sobre as transformações históricas na percepção, presente tanto entre leigos quanto entre profissionais, de que a saúde da população ultrapassa questões exclusivamente orgânicas. A medicina urbana francesa descrita por Michel Foucault (2008) já apresentava preocupação com o impacto que o ambiente poderia causar na manutenção do estado de saúde. Assim, o final do século XVIII foi marcado por uma intensa preocupação com saneamento e condições sanitárias em geral, em especial em grandes aglomerações. Anos mais tarde, a influência de questões socioculturais na saúde permaneceria forte nos discursos eugênicos, principalmente no higienismo neolamarckista, segundo o qual hábitos e comportamentos adquiridos poderiam ser repassados à prole (Stepan, 2004). Cuidar da saúde da população, pois, significava desenvolver políticas de controle e fiscalização de práticas consideradas nocivas. 0 mais interessante para nossa discussão é que, nesse início de século XX, já podemos perceber a importância que políticas de saúde tinham para a população. Havia na sociedade uma forte crítica ao que era percebido como "sanitarismo autoritário", crítica que teve na Revolta da Vacina de 1910 um de seus mais dramáticos exemplos. Porém, a participação da sociedade no desenvolvimento e na aplicação de políticas de saúde permanecia, de certa forma, periférica. 0 modelo de proteção social brasileiro dos anos 1950, por exemplo, se organizava por duas linhas de atuação: uma "cidadania invertida”, marcada por medidas compensatórias e caritativas, desenvolvidas por voluntários numa estrutura pulverizada e descontínua; ou uma "cidadania regulada", na qual eram beneficiários das políticas de saúde apenas aqueles(as) inseridos(as) nas categorias profissionais (Costa; Vieira, 2013). Em âmbito internacional, é interessante destacarmos que, ainda em 1948, a Organização Mundial da Saúde (OMS) desenvolve a noção ampliada de saúde, segundo a qual o estado de saúde decorre de um bem-estar biopsicossocial, de forma que é impossível pensarmos no processo saúde-doença desconsiderando os marcadores sociais da diferença.

A noção de "medicina comunitária" que se estabelece nas décadas de 1960-1970 traz, de forma bastante prática, uma preocupação com certa "determinação social" da saúde. Conforme Tambellini e Schütz (2009), essa percepção cresce a partir do documento do Governo canadense que ficou conhecido como Relatório Lalonde. Visando a reforma do sistema de saúde canadense, Marc Lalonde termina por escrever o primeiro documento governamental a reconhecer oficialmente que o paradigma biomédico é insuficiente para tratar a saúde da população. A qualidade da saúde não equivale à qualidade do atendimento médicosanitário, mas depende de quatro elementos: (1) biologia, (2) ambiente, (3) estilos de vida e organização do sistema de saúde e (4) determinantes da saúde não médicos. Vale ressaltar que Lalonde não objetivava um rompimento epistemológico, mas uma redução de gastos públicos. Ainda assim, colocou a 
situação social da população sob os holofotes dos formuladores de políticas de saúde. Em paralelo, no Brasil, a V Conferência Nacional de Saúde, em 1975, discute a saúde de populações marginais com a presença de seus representantes. Nessa mesma linha, a criação do Centro Brasileiro de Estudos em Saúde (Cebes), no ano seguinte, reafirma a luta por um sistema de saúde público, universal e com participação popular.

Neste breve histórico, é impossível não mencionar a importância da famosa Conferência Internacional sobre Cuidados Primários de Saúde, ocorrida em Alma-Ata em 1978, que estabelece a saúde como um direito humano fundamental e o foco estratégico em sua prevenção e promoção. Porém, ainda que a participação comunitária tenha sido considerada essencial nesse contexto, ela permanecia associada à demanda por extensão da cobertura dos serviços de saúde para áreas/populações marginalizadas. De toda forma, a conferência marca a inclusão do "social" nos determinantes de saúde já mencionados no Relatório Lalonde. Vale também o destaque de que, nesse período, a percepção dos determinantes sociais seguia a perspectiva do materialismo histórico, pensando a determinação social prioritariamente a partir de condições de trabalho e renda, conforme descrito por Barata (2009). Não podemos deixar de mencionar que, ainda que outros marcadores sociais sejam tão ou mais importantes, classe social, trabalho e renda continuam sendo essenciais para o processo de saúde-doença.

Na década de 1980, acompanhando a efervescência dos movimentos sociais durante o processo de redemocratização no Brasil, o pensamento sanitário avança para incluir a participação social também na formulação e no desenvolvimento das políticas de saúde, elevando o movimento social de objeto a sujeito nas ações em saúde no país. Como bem colocado por Nunes (1994), com a organização da medicina social, há a inclusão da ideia de determinação social da doença. O surgimento da saúde coletiva, com sua tripla qualificação (campo de saberes, âmbito de práticas e movimento social), cristaliza a necessidade de superação do paradigma biomédico. Assim, na VII Conferência Nacional de Saúde, em 1980, duas posições sobre participação social estiveram presentes. Uma, mais funcionalista, via na participação da comunidade a solução para problemas de saúde de populações marginais, mantendo a abordagem anterior. Por outro lado, crescia a percepção da presença comunitária como instrumento de redemocratização, buscando novos canais de expressão e oportunidades para os diversos grupos sociais. Essa dicotomia se aprofunda na VIII Conferência Nacional de Saúde, em 1986 - vale ressaltar, a primeira com representação popular decorrente de mobilização prévia. Em que pese o inegável avanço de defender a saúde como direito universal resultante de condições de vida da população, novamente concorriam duas acepções da participação popular: uma mais principiológica, que localizava essa participação na luta pela redemocratização, marcando a educação popular como uma ação estratégica em saúde; e outra mais funcionalista, que entendia a participação popular como um recurso dos excluídos para a garantia do acesso a serviços e cuidados de saúde (Costa; Vieira, 2013).

De toda forma, a Constituição Brasileira de 1988 institucionaliza a participação popular no chamado Sistema de Conselhos-Conferências, que tem como marco legal a ideia de participação social como um princípio do SUS (Lei no 8.080/1990), sendo devidamente estruturado segundo a Lei ${ }^{0}$ 8.142/1990 (Brasil, 1990). A década de 1990 veria a ascensão dos conselhos, com repasse federal de verbas para estados e municípios, conforme estabelecido pelas Normas Operacionais Básicas do SUS. Internacionalmente, é preciso destacar a importância do que ficou conhecido como Ciclo Social da Organização das Nações Unidas (ONU), um período no qual questões socioculturais ganharam importância em diferentes discussões. Dentre muitos exemplos, a Conferência Internacional sobre População e Desenvolvimento (realizada no Cairo em 1994) e a IV Conferência Mundial sobre a Mulher (realizada em Pequim em 1995) definiram parâmetros internacionais para os direitos sexuais e reprodutivos, colocando marcadores sociais como gênero e sexualidade no centro das discussões, por vezes se sobrepondo à classe social, marcador até então prioritário.

Ainda que legalmente garantida, a participação popular na saúde permanecia sendo vista de forma 
divergente; Dagnino (2004, passim) traz uma ótima descrição das sutilezas dessa diferença no que nomeia como "confluência perversa". Ou seja, a noção de que há grande importância na "participação ativa da sociedade" é difundida entre dois projetos políticos antagônicos: um classificado como neoliberal (estado mínimo e transferência de responsabilidades, participação voluntária, parceria público-privada) e outro de cidadania ativa (redemocratização e participação na tomada de decisões, defesa das políticas públicas, sociedade organizada e participante em conselhos e conferências).

Se o projeto neoliberal teve maior relevância na gestão na década de 1990, a mudança no Governo Federal nos anos 2000 trouxe maior aproximação ao ideal de cidadania ativa. No ano de 2006, por exemplo, é criada a Comissão Nacional sobre Determinantes Sociais de Saúde, seguindo os moldes da comissão de mesmo nome da OMS, criada dois anos antes. Porém, o relatório da Comissão nacional traz uma visão ainda reducionista da determinação social, estando focada numa abordagem gerencialista da saúde e de seus recursos (Tambellini; Schütz, 2009). Essa é uma crítica que se tornou comum à noção de determinação social da doença. Conforme argumenta Roberto Nogueira (2009), o conceito de “determinantes sociais" incita uma relação causal, baseada numa visão positivista do social que mantém forte a dicotomia entre natureza e cultura. De um ponto de vista antropológico, seria mais adequado falarmos em desigualdades sociais que afetam a saúde do que numa determinação, que termina por soar imutável ou de difícil mobilidade. Assim, uma melhor definição para a desigualdade social em saúde nos é dada pela perspectiva teórica nomeada por Rita Barata como "ecossocial”, que veria a desigualdade social como "diferenças no estado de saúde entre grupos definidos por características sociais, tais como riqueza, educação, ocupação, raça e etnia, gênero e condições do local de moradia ou trabalho" (Barata, 2009, p. 11). Seriam "situações que implicam algum grau de injustiça, isto é, diferenças que são injustas porque estão associadas a características sociais que sistematicamente colocam alguns grupos em desvantagem com relação à oportunidade de ser e se manter sadio" (Barata, 2009, p. 12). Concordando com a autora, Bagrichevsky et al. (2013) descrevem como as desigualdades sociais em saúde afetam a equidade tanto de forma horizontal quanto vertical, além de impactarem também o princípio de universalidade, já que dificultam o acesso da população acometida aos serviços de saúde e cuidado. Por outro lado, permanecer na ideia de determinação social pode nos levar a ferir ainda outro princípio do SUS, a integralidade, ao construir políticas para grupos sociais específicos em função de um olhar unidimensional, que enxerga um marcador social da diferença por vez. Nesse ponto, julgamos interessante incorporar o conceito de interseccionalidade trazido por Kimberlé Crenshaw (2002), que leva à percepção de que os diferentes marcadores sociais interagem entre si, criando novas configurações, muito além de uma mera "soma" de posições hierarquicamente desfavorecidas.

Independentemente dessas críticas, a noção da influência do lugar social no estado de saúde de indivíduos e populações tem impactos muito diretos e pragmáticos no cotidiano do serviço de saúde, sendo inquestionável sua utilidade na Atenção Básica e para a prevenção/promoção da saúde, especialmente no âmbito da Saúde da Família e da Humanização do SUS. Para Fabíola Zioni e Márcia Faria Westphal (2007), uma forma eficaz de explorar ao máximo as potencialidades do conceito de desigualdade social em saúde, evitando o reducionismo já mencionado, seria justamente a participação popular nas ações de saúde. É nessa perspectiva que se enquadra a experiência que desenvolvemos em sala de aula na disciplina de Aisc II. Nossa proposta é justamente aproximar os graduandos em saúde coletiva de diferentes movimentos sociais, que não apenas executam ações previamente definidas de acordo com as prioridades da gestão, mas formulam, aplicam e fiscalizam criticamente as políticas de saúde. Por meio da fala de militantes ou visitando espaços organizados e geridos pela militância, os(as) graduandos(as) têm uma abordagem prática e orgânica da participação popular e da importância de considerar as desigualdades sociais em saúde não a partir do olhar distanciado da academia, mas do cotidiano e das críticas reais trazidas pelas populações marginalizadas.

Descreveremos adiante essas visitas e rodas de conversa com ativistas e representantes das 
temáticas ${ }^{2}$ com alguns relatos apresentados pelos alunos. Evidentemente, não teremos espaço aqui para discutir todas as nuances desses encontros, debates e descrições dos relatórios dos alunos. Nos concentraremos em destacar alguns aspectos pertinentes ao encontro da Antropologia com a Saúde Coletiva. Cabe aqui destacar que nossos alunos são em sua maioria, jovens provenientes de famílias de baixa renda e habitantes da periferia urbana do Rio de Janeiro e dos municípios da Baixada Fluminense.

\section{A experiência na disciplina Ações Integradas em Saúde Coletiva II}

Como introdução à disciplina, é realizada uma aula expositiva sobre etnocentrismo, relativismo, alteridade e respeito à diferença. Diante disso, outros conceitos-chave, como cultura e sociedade, são apresentados e problematizados, e os alunos convidados a refletir sobre o tema. Para isso, o livro de Everardo Rocha (1985), O que é etnocentrismo, da coleção Primeiros Passos, é de grande ajuda. Um texto utilizado como exercício extremo de alteridade é o de Horace Miner (1976), intitulado "Ritos corporais entre os nacirema". Nesse texto, o autor descreve uma suposta tribo exótica e seus costumes estranhos de desenvolver rituais em relação ao corpo, de forma a temer veementemente doenças. Os alunos debatem o texto, inicialmente, em grupo, e depois no grande grupo. Geralmente, há grande perplexidade diante desses "estranhos rituais", e quando finalmente é esclarecido que o autor trata de nossa própria sociedade, a perplexidade é ainda maior, o que permite uma compreensão na "prática" dos conceitos de etnocentrismo e relativização. Também são utilizados vídeos e relatos de experiências de alteridades diversas. Nesse momento, é interessante que os alunos reconheçam a importância da relativização de outros conhecimentos "não científicos" e a necessidade de se despir de preconceitos que fatalmente nutrimos diante do diferente, de forma a desenvolver futuramente uma práxis mais humanizada.
Uma segunda aula trata de questões históricas e teóricas sobre movimentos sociais, participação e controle social. Desigualdades sociais, conflitos e mobilizações sociais que surgem no espaço público são conceitos importantes para examinar vários processos sociais contemporâneos.

Devido ao critério de discutirmos temas emergentes, podem ocorrer pequenas variações de visitas ou debates ofertados de um ano para o outro. Nos anos de 2017 e 2018, houve alterações de locais de visita sem perda do conteúdo programático.

Apresentaremos adiante os locais em que foram realizadas as visitas, bem como as temáticas problematizadas. Os graduandos foram levados à Ocupação Vito Giannotti, no ano de 2017, e à Ocupação Manuel Congo, no ano de 2018, com o intuito de os aproximar da realidade da luta por moradia e refletir sobre as correlações com os determinantes sociais de saúde. Grande parte da população não tem acesso a espaços públicos, ambiente saudável, moradia digna e infraestrutura, o que torna o direito à cidade um objetivo de vários movimentos sociais. Em 2001, é criado o Estatuto da Cidade, que define a função social da propriedade urbana (Rodrigues, 2004, p. 11):

Trata-se de uma lei construída com a ativa participação dos movimentos da sociedade civil que lutam pela reforma urbana. A ênfase dos movimentos sociais, nacionais e internacionais, tem sido questionar a supremacia do direito de apropriação, da propriedade do solo, e das edificações urbanas em relação ao direito à vida. É necessário, para que a cidade cumpra sua função social, que a propriedade individual seja, no mínimo, relativizada, para garantir o acesso a todos os moradores à cidade.

A experiência da visita, na qual os alunos conseguiram dimensionar a organização do movimento e o relato de moradores do local, desconstruiu a imagem criminalizante dos movimentos de ocupação repassada pela imprensa, conforme o relato de uma aluna: $\varepsilon u$

\footnotetext{
2 Gostaríamos de agradecer aqui os(as) convidados(as) que se dispuseram a participar da disciplina, alguns(mas) repetidas vezes, e contribuir com esse debate: Mario Carvalho, Katiuscia Ribeiro, Jacqueline Gomes de Jesus, Georgia Bello, Veriano Terto, Mauro Nunes, Maria de Fátima Silva, Marisa Chaves, Júlia Ventura, Henrique Vieira, Cesar Paro, Julio Moreira e Demian Melo.
} 
sempre pensei que eram vândalos que invadiam as residências, mas não, são pessoas que se organizam, ocupam prédios do governo que estão abandonados, arrumam ele direitinho... foi muito importante para mim essa visita (Andreza).

A mesma desconstrução da lógica de descriminalização dos movimentos sociais ocorreu na visita ao espaço de comercialização de produtos produzidos pelo Movimento dos Trabalhadores Rurais Sem Terra (MST). Fundado oficialmente em 1984, a partir de experiências de luta por terra, incorporou nos seus ideais questões políticas e ideológicas, transformando-se em luta pela reforma agrária. Para a organização do movimento, foram criadas diferentes instâncias representativas, visando a divisão de tarefas e discussões específicas. Uma dessas instâncias é o setor de saúde que tem como objetivo lutar pelo direito à saúde, pelo reconhecimento de práticas populares e pelo enfrentamento do modelo biomédico de saúde dominante e o agronegócio. Aproximando-se dos referenciais orientadores da Reforma Sanitária,

O Setor de Saúde busca a construção de experiências que expressam a saúde como resultado da melhoria das condições de vida, do acesso à terra e à reforma agrária, ressaltando a importância do saneamento, da moradia, do incentivo à produção agrícola, da educação e do acesso aos serviços de saúde. Tais experiências buscam, ainda, considerar as formas de cuidado à saúde das famílias, visando o reconhecimento e valorização desses saberes. (Ruckert; Aranha, 2018, p. 118)

A roda de conversa com os integrantes do movimento, responsáveis pelo núcleo de saúde, propiciou reflexões sobre reforma agrária, agrotóxicos e seus impactos à saúde da população. Dessa forma, os alunos puderam compreender as lutas do movimento em relação aos grandes latifundiários e aos interesses do agronegócio, tema atual, importante e com consequências para a saúde de toda a população.
A visita à Maré, complexo composto por 16 favelas, com aproximadamente 137 mil moradores, foi definida como um importante contato com a realidade do contexto social do município do Rio de Janeiro, que apresenta especificidades territoriais. Os graduandos conheceram a organização não governamental (ONG) Redes da Maré, ${ }^{3}$ que desenvolve projetos sociais em cinco eixos estruturantes para a melhora na qualidade de vida e nos direitos da população: desenvolvimento territorial, direito à segurança pública e acesso à justiça, educação, arte e cultura e identidades e memórias. Estima-se que vivam em favelas no município cerca de 1 milhão e meio de habitantes, de acordo com o Censo de 2010 (Cavallieri; Vial, 2012) - esses dados já estão bem desatualizados. Essa situação se torna um problema de saúde pública, tendo em vista a falta de infraestrutura adequada para o desenvolvimento de uma vida saudável.

A ida à favela sempre gera expectativas em relação à violência local. Em virtude disso, os integrantes da ONG acompanharam os alunos desde a entrada no complexo até a saída, ao final da visita. Na avaliação da disciplina, perguntou-se aos alunos se a ida à favela havia gerado algum impacto. Sendo a maioria dos alunos moradores de comunidades carentes, a resposta foi negativa. A fala de um aluno ilustra esse aspecto: Não, pois vivencio a realidade da favela há algum tempo, a população que habita essas comunidades, as mazelas que as cercam e os dilemas diários que os indivíduos passam (Paulo). Por outro lado, outra avaliação de uma aluna chamou atenção ao dizer: vocês não disseram como deveríamos nos comportar (Helena) - o que mostra o grande imaginário e as fantasias que são associadas à vida na favela e a importância de incluirmos essa discussão em disciplinas universitárias, uma vez que o campo de atuação do sanitarista implica avaliação e planejamento de ações em territórios de grande vulnerabilidade e violência.

Os graduandos tiveram a oportunidade também de conhecer uma ONG que trabalha com violência à mulher: Movimento de Mulheres de São Gonçalo; essa é uma temática de extrema relevância para a saúde coletiva. A ONG atua desde 1989, coordenada pela assistente social Marisa Chaves, com o objetivo 
de defender os direitos humanos em relação a mulheres, crianças e adolescentes, com ênfase nos enfrentamentos de violência doméstica. Há acolhimento especializado a esse público e ajuda material para ele por meio do recolhimento de doações (móveis e cestas básicas). Algumas alunas, especialmente, referiram ter ficado afetadas pelos relatos sobre violência. Elas compreenderam a importância desse espaço, uma vez que as políticas públicas são insuficientes para dar conta do problema: A visita me fez observar como devemos estar mais sensiveis para esse problema e os variados problemas de saúde que podemos enfrentar (Rosana).

Uma das premissas da disciplina é mostrar como determinados problemas sociais são problemas de saúde pública (Schraiber; D’Oliveira; Couto, 2006). 0 relato de uma aluna mostra como é possível, pelo contato com esse tipo de organização, onde são apresentados alguns casos e o trabalho é desenvolvido, fazer essa relação:

Um fato que chamou bastante atenção no momento da visita foi o desinteresse do governo com ações destinadas a essa população. Tanto para o tratamento físico quanto psicológico, já que o dano psicológico muitas vezes é maior que o físico e não se consegue auxílio para isso. Ao meu ver, as UBS deveriam ter capacidade de atender esse tipo de problema, dando o suporte necessário com uma equipe treinada, e, principalmente, garantindo o anonimato e o sigilo do caso, pois sabemos que muitas UBS ficam localizadas em comunidades onde todos se conhecem. Como gestores em Saúde Coletiva, devemos olhar para todas essas situações. (Eliana)

As violências domésticas, de gênero, são perpetradas, em sua maioria, por parceiros íntimos. Tal condição gera grande vulnerabilidade a essas mulheres, provocando impactos em sua saúde. Estudos mostram que as mulheres em situação de violência procuram muito mais os serviços de saúde com queixas vagas e problemas de saúde mental, além de machucados físicos (Pierotti; D’Oliveira; Terra, 2018). É consenso que essa é uma questão de saúde pública, e há que se conhecer sua complexidade. Observamos que sensibilizar os alunos a essa temática é de extrema relevância e pertinência ao contexto social atual em que vivemos.

Os alunos participaram da reunião do Conselho Municipal de Saúde do município do Rio de Janeiro, a fim de vivenciar um espaço importante de participação e controle social. Os Conselhos de Saúde, criados em 1990 com a Lei no 8.142, têm como objetivo aproximar a população da gestão, com a possibilidade de construção conjunta de prioridades de ações, tomadas de decisão, monitoramento e fiscalização.

O Conselho de Saúde, em caráter permanente e deliberativo, órgão colegiado composto por representantes do governo, prestadores de serviço, profissionais de saúde e usuários, atua na formulação de estratégias e no controle da execução da política de saúde na instância correspondente, inclusive nos aspectos econômicos e financeiros, cujas decisões serão homologadas pelo chefe do poder legalmente constituído em cada esfera do governo. (Brasil, 1990)

As reuniões acontecem na sede da Prefeitura Municipal do Rio de Janeiro. Especialmente em uma das visitas da disciplina, a pauta de discussão foi o controle do orçamento e o monitoramento das ações de algumas Coordenadorias de Saúde, marcada por discursos exaltados e inflamados de alguns representantes e conselheiros. Esse fato em particular gerou atenção nos alunos, e foi relatado por um estudante no diário de observação desta forma:

Ao iniciar a reunião, a interação era bem amigável, porém, apesar de todos estarem ali com o mesmo objetivo, em determinado momento surgiu um atrito. Foi possivivel comparar com meus tempos de escola, onde, no intervalo, os alunos se separavam em grupos de acordo com seus interesses específicos, ignorando os demais. (João)

Com raras exceções, essa visita é a primeira participação dos alunos em uma reunião do Conselho Municipal de Saúde. E, para futuros gestores, bem como para cidadãos, revela-se a importância dessa participação, como demonstrado nos relatos adiante:

Aquele local, aquelas pessoas e aqueles temas, tudo respira saúde coletiva. Tudo ali se trata de 
gestão, planejamento, promoção e relação direta da população com o SUS. (Ana Maria)

Nessa visita, que se revelou bastante promissora ao nos apresentar a estrutura e o centro da discussão do nosso município, nos fez perceber o quão ínfima é a nossa participação nas representações da cidade. $O$ que nos é apresentado pela mídia, o que acreditamos estar contribuindo, não chega nem perto dos problemas crescentes da nossa sociedade. Ingressar ativamente, mesmo que seja pouco a pouco, nas questões sociais de nossa comunidade, não por obrigação, mas como cidadãos, poderia, quem sabe, contribuir como uma voz nos conselhos municipais. (Elisângela)

Foram realizados também debates em aulas abertas para a universidade em geral sobre racismo e questões da etnicidade, intolerância religiosa e saúde da população transexual, mostrando como esses temas são polêmicos; os debates em sala de aula demonstram como há definições e concepções múltiplas sobre o tema, que estão em constantes negociações e conflitos. Essas questões são emergentes no Brasil atual e merecem atenção quanto a sua importância enquanto movimentos sociais de luta por direitos. A articulação com a saúde é bem problematizada nesses encontros, mostrando como as desigualdades de gênero, raça e crença a afetam e questionando o determinismo biológico.

Os eventos relacionados às eleições em 2018 nos levaram a realizar uma discussão sobre o fascismo e os impactos à saúde da população. Para isso, foi convidado um professor de história, Demian Melo, que é referência e militante dessa temática. Essa aula, nomeada pelos participantes como "aula magna" foi considerada de extrema relevância tendo em vista o momento político emergente, com propostas de inclusão no programa do curso e maior divulgação a todo o campus universitário, para que alunos de outros cursos também pudessem adquirir esse conhecimento.

Em todos os encontros, é sugerido um referencial teórico sobre o tema, e a metodologia é pautada na participação dos alunos, sentados em círculos, que proporcionam melhor interação para rodas de conversa. No decorrer da disciplina, sempre encorajase os estudantes a identificar os vieses da cultura, incluindo sua própria, na formação de seu sistema de crenças. Ao estimular os estudantes a identificar preconceitos, estigmatização e processos de exclusão social no campo da saúde, estimula-se uma postura crítico-reflexiva que reverbera em suas práticas, de forma que elas sejam mais éticas e voltadas para um cuidado mais humanizado.

\section{Considerações finais}

Os temas abordados na disciplina de Aisc II mostram igualmente a necessidade da intersetorialidade das intervenções. 0 incentivo à participação nas organizações e ações comunitárias e nas iniciativas dos coletivos e movimentos sociais organizados possibilitam o empoderamento das populações e geram condições de autonomia dos indivíduos e grupos. Assim, é imprescindível o debate em torno de intervenções que estimulem práticas comunitárias e de organização política e social.

O exercício da relativização do outro faz parte da tradição antropológica, sendo essa a principal contribuição da disciplina para o descentramento do olhar nas práticas de intervenção em saúde. Esse exercício é fundamental para desconstruir e desessencializar noções como saúde e doença, prevenção e risco, de forma a trazer novas perspectivas e dimensões dos comportamentos humanos. Cabe também, nesse contexto de busca constante do conhecimento do outro, transmitir aos alunos o cuidado para não estabelecermos um discurso reificado do outro. Dessa maneira, tomamos como princípio que professores devem ser interlocutores com disposição à escuta, alguém a estimular um discurso reflexivo sem impor modelos prescritivos de atuação. Para isso os debates em aula, a troca de experiências e os relatos de situações vividas permitem a aquisição de conhecimento não somente por meios cognitivos, mas também afetivos, na medida em que lidam com valores, crenças e comportamentos de si próprio e do outro.

Há necessidade urgente de levarmos em consideração o contexto social das pessoas envolvidas nas práticas de intervenção em saúde, de modo a considerar as dificuldades materiais, subjetivas e culturais de inclusão dos indivíduos nos princípios de saúde. Isso significa ampliar a abordagem dos problemas, trazendo à tona discussões sobre gênero, 
raça, classe social, cidadania e acesso aos serviços públicos de qualidade. Significa também trabalhar com metas difíceis de serem mensuradas, como desconstruir preconceitos, desfazer medos e tabus, colocar-se no lugar do outro e respeitar as diferenças.

Nas avaliações da disciplina, utilizamos duas perguntas: "Como a disciplina auxiliou minha formação como sanitarista?" e "O que poderia incluir ou melhorar?”. Os relatos descrevem o caráter revelador dos problemas sociais e das desigualdades sociais e culturais para a atuação do sanitarista. Os relatos citados adiante ilustram esse aspecto:

A disciplina foi muito rica tratando das minorias e apresentando alguém do meio (nada melhor do que alguém da própria comunidade para falar). Foi possivel compreender mais coisas que eu não tinha conhecimento profundo e conhecer coisas novas, além de nos fazerrefletir e pensar tanto enquanto pessoas, como profissionais de saúde que buscarão meios de enfrentar tantas desigualdades existentes. (Leonardo)

A disciplina auxiliou no conhecimento de projetose programas que atuam diretamente nas necessidades da população, sendo essa população muitas vezes excluída, vivendo à margem da sociedade. Fez pensar que, como sanitaristas, devemos realizar ações que atendam as condições de saúde para a população como um todo. Os excluídos devem ser inseridos nas políticas públicas, de forma a exercer seu papel de cidadão. (Carolina)

Essa disciplina me auxiliou em uma aproximação da realidade, das grandes lutas, batalhas e preconceito. Despertou um olhar [de] que devemos defender a equidade em todos os âmbitos sociais possíveis, me tornando um aluno mais ativo, perseverante $e$ consciente. (Liliane)

Por isso consideramos de suma importância que, mesmo quando permanecia dentro de sala da aula, a turma não estava meramente assistindo a uma aula expositiva, teórica, mas tinha contato com alguém que sente na pele e na carne como os marcadores sociais da diferença geram doença e iniquidades em saúde. De um ponto de vista didáticopedagógico, podemos ainda acrescentar como esse formato coaduna com as propostas educacionais de Paulo Freire, ao colocar a realidade social no centro do processo de ensino-aprendizagem, formando não apenas bacharéis em saúde coletiva, mas profissionais conscientes, humanizados e aptos(as) para conduzir a transformação social.

\section{Referências}

BAGRICHEVSKY, M. et al. Desigualdades sociais em saúde e práticas corporais: um exercício singular de análise. Saúde e Sociedade, São Paulo, v. 22, n. 2, p. 497-510, 2013.

BARATA, R. B. Como e por que as desigualdades sociais fazem mal à saúde. Rio de Janeiro: Fiocruz, 2009.

BARROS, N. F. A construção da medicina integrativa: um desafio para o campo da saúde. São Paulo: Hucitec, 2008.

BRASIL. Lei no 8.142, de 28 de dezembro de 1990. Dispõe sobre a participação da comunidade na gestão do Sistema Único de Saúde (SUS) e sobre as transferências intergovernamentais de recursos financeiros na área da saúde e dá outras providências. Diário Oficial da União, Brasília, DF, 31 dez. 1990. Seção 1, p. 25694.

CAVALLIERI, F.; VIAL, A. Favelas na cidade do Rio de Janeiro: o quadro populacional com base no Censo 2010. Coleção Estudos Cariocas, Rio de Janeiro, n. 20120501, p. 1-18, 2012.

COSTA, A. M.; VIEIRA, N. Participação e controle social em saúde. In: FUNDAÇÃO OSWALDO CRUZ. A saúde no Brasil em 203o: prospecção estratégica do sistema de saúde brasileiro: organização e gestão do sistema de saúde. Rio de Janeiro, 2013. v. 3. p. 237-271.

CRENSHAW, K. Documento para o encontro de especialistas em aspectos da discriminação racial relativos ao gênero. Estudos Feministas, Florianópolis, v. 10, n. 1, p. 171-188, 2002.

DAGNINO, E. Sociedade civil, participação e cidadania: do que estamos falando? In: MATO, D. (Coord.). Políticas de ciudadanía y sociedad civil en tiempos de globalización. Caracas: FaCES, 2004. p. 95-110. 
DURKHEIM, E. Sociologia e filosofia. São Paulo: Ícone, 1994.

FOUCAULT, M. Microfísica do poder. São Paulo: Graal, 2008.

KUROKAWA SILVA, N.; VENTURA, M.; FERREIRA, J. Graduação em Saúde Coletiva e o processo de construção de cenários práticos. Tempus: Acta de Saúde Coletiva, Brasília, DF, v. 7, n. 3, p. 91-101, 2013.

LATOUR, B.; WOOLGAR, S. A vida de laboratório: a produção dos fatos científicos. Rio de Janeiro: Relume-Dumará, 1988.

LORENA, A. C. et al. Graduação em saúde coletiva no Brasil: onde estão atuando os egressos dessa formação? Saúde e Sociedade, São Paulo, v. 25, n. 2, p. 369-38o, 2016.

MINAYO, M. C. et al. Possibilidades e dificuldades nas relações entre ciências sociais e epidemiologia. Ciência \& Saúde Coletiva, Rio de Janeiro, v. 8, n. 1, p. 97-107, 2003.

MINER, H. Ritos corporais entre os nacirema. In: ROONEY, A. K.; DE VORE, P. L. (Org.). You and the others: readings in introductory anthropology. Cambridge: Erlich, 1976. Não paginado. Disponível em: <https://bit.ly/2H24xPq >. Acesso em: 3 maio 2019 .

MORIN, E. A cabeça bem-feita: repensar a reforma, reformar o pensamento. Rio de Janeiro: Bertrand Brasil, 2006.

NOGUEIRA, R. P. Determinantes, determinação e determinismo sociais. Saúde em Debate, Rio de Janeiro, v. 33, n. 83, p. 397-406, 2009.

NUNES, E. D. Saúde coletiva: história de uma ideia e de um conceito. Saúde e Sociedade, São Paulo, v. 3, n. 2, p. 5-21, 1994.

NUNES, E. D. Ciências sociais e humanas em saúde: incorporando a teoria. Ciência \& Saúde Coletiva, Rio de Janeiro, v. 19, n. 4, p. 1004, 2014.

NUNES, E. D. et al. O uso das ciências sociais nas escolas médicas: reunião de experiências. Ciência \& Saúde Coletiva, Rio de Janeiro, v. 8, n. 1,

p. 209-225, 2003.

PIEROTTI, C. F.; D'OLIVEIRA, A. F. P. L.; TERRA, M. F. A situação de violência doméstica de gênero na atenção primária à saúde. Arquivos Médicos dos Hospitais e da Faculdade de Ciências Médicas da Santa Casa de São Paulo, São Paulo, v. 63, n. 1, p. 8-12, 2018.

ROCHA, E. O que é etnocentrismo. São Paulo: Brasiliense, 1985.

RODRIGUES, A. M. Estatuto da cidade: função social da cidade e da propriedade: alguns aspectos sobre população urbana e espaço. Cadernos Metrópole, São Paulo, n. 12, p. 9-25, 2004.

RUCKERT, B.; ARANHA, A. V. S. Lutar por saúde é lutar por reforma agrária: estudo sobre práticas de saúde no Movimento dos Trabalhadores Rurais Sem Terra. Saúde e Sociedade, São Paulo, v. 27, n. 1, p. 116-127, 2018

SCHRAIBER, L.; D’OLIVEIRA, A. F. P. L.; COUTO, M. T. Violência e saúde: estudos científicos recentes. Revista de Saúde Pública, São Paulo, v. 40, p. 112-120, 2006. Número especial.

STEPAN, N. L. Eugenia no Brasil, 1917-1940. In: HICHMAN, G.; ARMUS, D. (Org.). Cuidar, controlar, curar: ensaios históricos sobre saúde e doença na América Latina e Caribe. Rio de Janeiro: Fiocruz, 2004. p. 331-391.

TAMBELLINI, A.; SCHÜTZ, G. Contribuição para o debate do Cebes sobre a "Determinação social da saúde": repensando processos sociais, determinações e determinantes da saúde. Saúde em Debate, Rio de Janeiro, v. 33, n. 83, p. 371-379, 2009.

UFRJ - UNIVERSIDADE FEDERAL DO RIO DE JANEIRO. Instituto de Estudos em Saúde Coletiva. Centro de Ciências da Saúde. Projeto político pedagógico do curso de graduação em saúde coletiva. Rio de Janeiro, 2010.

ZIONI, F.; WESTPHAL, M. F. O enfoque dos determinantes sociais de saúde sob o ponto de vista da teoria social. Saúde e Sociedade, São Paulo, v. 16, n. 3, p. 26-34, 2007.

\section{Contribuição dos autores}

Todos os autores participaram da concepção, análise dos dados, redação do artigo e aprovação da versão final a ser publicada.

Recebido: 25/03/2019

Aprovado: 09/04/2019 